\title{
Co-occurrence of host plants associated with plant quality determines performance patterns of the specialist butterfly, Battus polydamas archidamas (Lepidoptera: Papilionidae: Troidini)
}

\author{
Rodrigo S. RIOS ${ }^{1}$, Cristian SALGADO-LUARTE ${ }^{1}$, Gisela C. STOTZ², ERnesto GIANOLI,3 \\ ${ }^{1}$ Departamento de Biología, Universidad de La Serena, Raúl Bitrán \#1305, La Serena, IV Region de Coquimbo 1720170, Chile; \\ e-mails: srrios@userena.cl, crisalga@gmail.com \\ ${ }^{2}$ Department of Biological Sciences, University of Alberta, Edmonton, Alberta, Canada; e-mail: stotzgisela@gmail.com \\ ${ }^{3}$ Departamento de Botánica, Universidad de Concepción, Concepción, Chile; e-mail: gianoli@gmail.com
}

Key words. Lepidoptera, Papilionidae, Troidini, Battus polydamas archidamas, Aristolochia, polydamas swallowtail, larval performance on host plants, host plant-induced preference, performance mosaic, plant quality

\begin{abstract}
In herbivorous insects, differences in the degree of specialization to host plants emerge when the distribution of an herbivore differs from that of its host plants, which results in a mosaic of populations differing in performance on the different host plants. Using a specialized butterfly, Battus polydamas archidamas Boisduval, 1936, which feeds exclusively on the genus Aristolochia, we test whether host plant co-occurrence and associated differences in host quality modify local adaptation in terms of larval preference and performance. We compared individuals from a monospecific host stand of Aristolochia chilensis with those from a mixed host stand of $A$. chilensis and $A$. bridgesii. Individuals were reared in a reciprocal transfer experiment in which source population and the host species fed to larvae were fully crossed in a two-by-two factorial experiment in order to quantify their preference, performance (development time, size and growth rate) and survival. Individuals from both populations preferred the species they ate during their larval development over the other host, which indicates host plant-induced preference with non-adaptive implications. Larvae from mixed and monospecific stands grew faster and survived better when reared on $A$. bridgesii than $A$. chilensis. Larvae from a monospecific host stand grew slower and fewer individuals survived under the same local conditions, which is contrary to expectations. Therefore, rearing the butterfly on $A$. bridgesii consistently resulted in better performance, which indicates that the monospecific population is less well adapted to its host than the mixed population. Variation in the occurrence of the two host plants in the two populations can result in divergent selection due to the variation in plant quality, which in this case could result in opposing adaptive processes.
\end{abstract}

\section{INTRODUCTION}

A wide range of herbivorous insects are highly host plant specific (Jaenike, 1990) presumably as a result of differential adaptation to those plants (Futuyma \& Moreno, 1988; Kassen, 2002). Specialization arises by way of a process of adaptation to a restricted subset of possible host plants and/or because of a lack of variation in host plants (Bolnick et al., 2002; Devictor et al., 2010; Poisot et al., 2011). Host adaptation in herbivorous insects involves an insect genotype $\mathrm{x}$ host genotype interaction leading to divergence in performance across multiple plant species or fixation of genotypes within these species (Via, 1990; Kawecki \& Ebert, 2004). Herbivore performance (i.e., development and/or survival) on different species of plants differs resulting in geographic differences in ecological outcomes or in the traits linked to the interaction (Zangerl \& Berenbaum, 2003; Toju \& Sota, 2006; Laukkanen et al., 2012) generating a mosaic of local performance (Thompson,
2005). This mosaic is often the product of spatial variation in the co-occurrence of potential host plants (Thompson $\&$ Cunningham, 2002). When there is more than one host species present in an area, the distribution of an herbivore often differs from that of its host plants and not all host plants occur in the same locality.

For insect herbivores, differences in host plant quality may result in spatial variation in selective pressures that are likely to lead to spatial divergence in patterns of host utilization (Endler, 1977; Thompson, 1999; Laukkanen et al., 2012; Stotz et al., 2013). Individuals within a population evolve under a particular local scenario of host quality and occurrence of host plants (Fox \& Morrow, 1981; Reznick \& Ghalambor, 2001; Kawecki \& Ebert, 2004), which when variable across populations, may promote adaptive divergence (Thompson, 2005) and differences in the degree of performance in terms of development and fitness (Fig. 1). For example, a specialist herbivore that historically occurs 


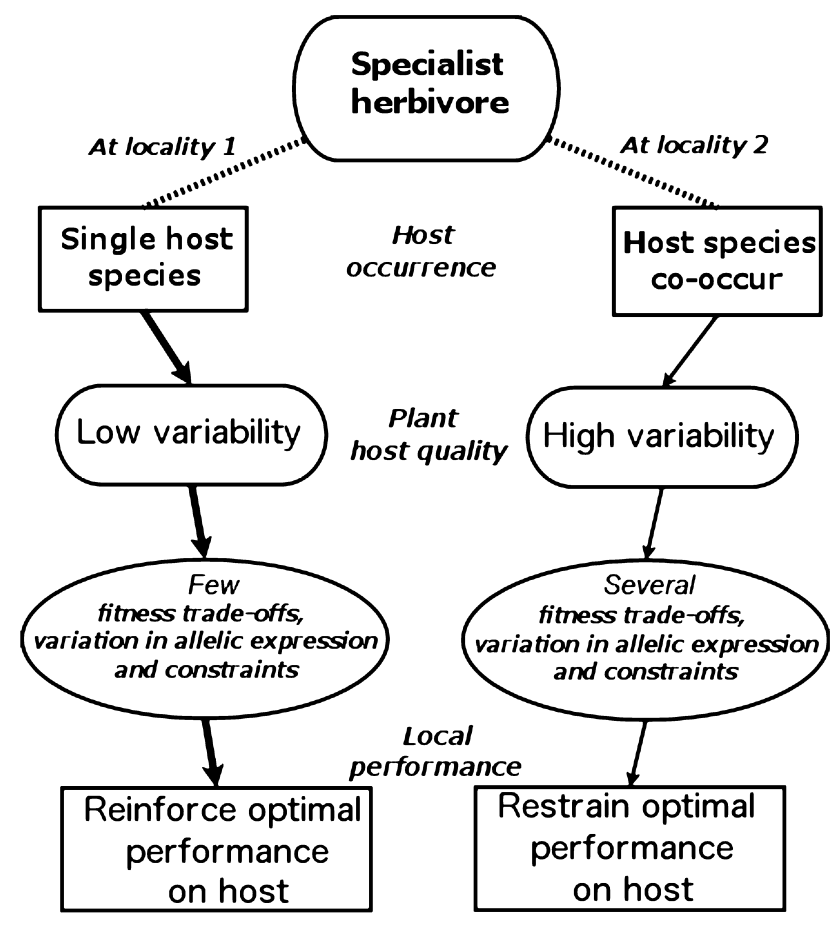

Fig. 1. Graphical representation of how host plant co-occurrence, through variation in host plant quality, can determine local performance in specialist herbivores. Variation in insect performance differs depending on the occurrence of one or more species of host plants, ultimately promoting adaptive divergence. Co-occurrence with more than one host plant should alter insect development, survival and reproduction when individuals feed indiscriminately because of trade-offs in fitness, differences in allelic expression and/ or constraints associated with feeding on alternative host plants. Trade-offs and variation in allelic expression on alternative host plants result from differences in plant quality. When more than one host is present trade-offs tend to operate more strongly in decreasing or relaxing optimal development and survival (performance) of individuals (thin arrows). When host species occur alone, performance is enhanced and/or reinforced (thick arrows). Dotted lines represent different geographical settings in terms of host plant occurrence.

locally with a single host plant should tend to show greater preference, life history performance, reproduction and survival on its sympatric host than on an allopatric host plant (Hereford, 2009; Poisot et al., 2011). Moreover, the performance of this herbivore should be greater on its original host plant than that of an herbivore from a different population feeding on the same plant (Kawecki \& Ebert, 2004). In contrast, herbivores that occur locally with more than one host plant, should show poorer performance; the assumption being that no insect genotype will be equally fit on all hosts. When, herbivores indiscriminately utilize hosts in sympatry, trade-offs in fitness on alternative host plants should result from differences in plant quality (i.e., plant defense or nutritional value), which coupled with physiological, morphological and/or developmental constraints limit optimal insect performance (Futuyma \& Moreno, 1988; Jaenike, 1990; Agrawal, 2000a; Kassen, 2002).

Even if trade-offs are not ubiquitous, however, differential expression of fitness components in different localities can still occur. These differences can be the result of allele substitutions at loci that have fitness consequences under certain conditions such as when host resources are only available in some habitats (Via \& Lande, 1985) or in processing secondary compounds specific to a certain host plant in the range used by a herbivorous insect (Kawecki, 1994). Therefore, it is expected that when several resources are available individuals are more likely to accumulate deleterious mutations and/or less likely to fix new adaptations (Kawecki, 1994; Whitlock, 1996) and show a greater adaptation in monospecific host stands.

Differences in insect performance on different host plants has been evaluated numerous times showing it is widespread in insect-plant interactions (e.g., Ehrlich \& Raven, 1964; How et al., 1993; Hougen-Eitzman \& Rausher, 1994; Van Zandt \& Mopper, 1998). However, effects of host plant co-occurrence and plant quality on insect performance have received far less attention (Jaenike \& Papaj, 1992; Stotz et al., 2013). Using the specialized butterfly Battus polydamas archidamas Boisduval, 1836, which feeds exclusively and depends entirely on plants of the genus Aristolochia to complete its development (Peña \& Ugarte, 1996), we evaluated the influence of host plant presence in modifying patterns of local adaptation. Only two host species of the genus Aristolochia occur within this butterfly's distributional range, Aristolochia chilensis and $A$. bridgesii (Peña \& Ugarte, 1996). Moreover, the distribution of $A$. bridgesii is nested within that of $A$. chilensis throughout its range (Riedemann et al., 2006). Therefore, populations of $B$. polydamas archidamas are found in either monospecific stands of $A$. chilensis or mixed stands with both species present. Specifically, we test the hypothesis that host plant (co-)occurrence alters insect development and/or survival (optimal performance) as a consequence of differences in plant quality that occurs when the number of hosts varies from one site to another. Accordingly, we predict that interspecific differences in host plant quality within a mixed host stand of Aristolochia should tend to restrain larval growth rates, development time, size and survival, as opposed to a monospecific host stand where performance on a particular host does not incur a fitness trade-off with alternative host plants and/or there are fewer differences in allelic expression (Fig. 1; see also Kawecki $\&$ Ebert, 2004). Moreover, larvae from the monospecific host stand should better discriminate $A$. chilensis and translate this choice into favourable life history performance traits by having higher growth rates, longer development time, greater size and increased survival.

\section{MATERIAL AND METHODS}

\section{System studied}

The Neotropical swallowtail, Battus polydamas, is a large and fairly conspicuous butterfly of the family Papilionidae. The upper sides of the wings are brown-black with a broad submarginal band of yellow spots on both the fore and hind wings (Peña \& Ugarte, 1996). B. polydamas has a wide distribution, extending from the south of the United States to Argentina (Peña \& Ugarte, 1996). Aposematic larvae of this species feed exclusively on plants of the genus Aristolochia, which are known to contain toxic compounds that include benzylisoquinoline alkaloids and aristolochic acids (Poonam et al., 2003). Toxic compounds are sequestered by 
larvae, making both caterpillars and adult butterflies unpalatable to potential predators (Pinto et al., 2011). In Chile, the subspecies $B$. polydamas archidamas occurs from the Atacama Desert $\left(27^{\circ}\right)$ to the Mediterranean region $\left(34^{\circ}\right)$, which coincides with the distribution of its two host plant species, $A$. chilensis and $A$. bridgesii (Peña \& Ugarte, 1996). Both are pipevines of the family Aristolochiaceae and endemic in Chile; while $A$. chilensis ranges from the Pacific coast to the Andean mountains $\left(26^{\circ} \mathrm{S}\right.$ to $\left.35^{\circ} \mathrm{S}\right)$ A. bridgesii is more restricted to the interior dry valleys $\left(28^{\circ} \mathrm{S}\right.$ to $30^{\circ} \mathrm{S}$ ). Given that the distribution of $A$. bridgesii is nested within that of A. chilensis, the former species tends to coexist locally with the latter.

Chilean species of Aristolochia are summer-deciduous scrambling herbaceous plants and have very similar vegetative, reproductive and growth habit characteristics (Riedemann et al., 2006). Flowering and fruiting occurs from August to December; pipe-shaped flowers are large $(\sim 8 \mathrm{~cm})$ and release an unpleasant odour that attracts flies for pollination (Stotz \& Gianoli, 2013). Fruits are dehiscent nuts, 3-4 cm long, bearing black seeds, 4-4.5 $\mathrm{mm}$ long. Twining stems have many lobed-alternate leaves forming dense foliage. The chemical composition of the aristolochic acids (AA) in these species is qualitatively similar; differences are found in the total amount and the relative proportion of the different AA, with $A$. bridgesii having more AA per mg of plant tissue and a higher relative proportion of phenolic AA than $A$. chilensis (Urzúa et al., 2009). Therefore, these host plants presumably differ in quality for $B$. polydamas. Studies conducted on the Aristolochia-Battus system have argued that AA play a crucial role in this specific plant-herbivore interaction (Sachdev-Gupta et al., 1993; Pinto et al., 2009a, b; 2011).

\section{Experimental design}

To assess the role of host co-occurrence and plant quality on larval performance we conducted a reciprocal transfer experiment. From November to December of 2011 we collected on three occasions a total of 50 egg clusters of $B$. polydamas. Each collection lasted a week and included eggs from two localities separated by a distance of $60 \mathrm{~km}$ : Totoralillo (coastal) and Antakari (interior). These populations differ in the host plant species available for B. polydamas larvae. Totoralillo is a semiarid coastal site with a large population of A. chilensis (monospecific stand), whereas Antakari is a dry interior valley site where both $A$. chilensis and A. bridgesii are dominant (mixed stand). At both localities Aristolochia is abundant ( $>200$ plants) over an area greater than 1 $\mathrm{km}^{2}$. Finding mixed stands with an adequate number of individuals of both host plants proved difficult; therefore, we used only these two sites in this study. To ameliorate to some degree the chance of a treatment effect being indistinguishable from chance effects, sampling at both sites was spaced-out in time (bi-weekly). Given that the Battus-Aristolochia system occurs in an arid environment and that the insect is multivoltine, generations of the butterfly are in effect different subpopulations that experience different environmental conditions during the course of a season.

During sampling, one egg cluster was collected per plant and sampled plants were separated from each other by at least $20 \mathrm{~m}$. Egg clusters were collected over a period of seven days in a season or until we reached our target sample size (50), which decreased the probability of collecting egg clusters from the same females and enabled us to sample individuals from more than one cohort for each population. During the collection of egg clutches, weather conditions varied between sites. At Totoralillo, a cloudy coastal site, the temperature was slightly lower (14-17 vs. $\left.16-19^{\circ} \mathrm{C}\right)$ and humidity higher $(50-70 \%$ vs. $30-45 \%)$ than at Antakari, the sunny interior site. Immediately after collection, egg clusters were divided in half and each half placed in a single
Petri dish and randomly assigned to one of the host plants for feeding in the laboratory, such that half of the emerging larvae per cluster were fed $A$. chilensis leaves and the other half $A$. bridgesii leaves throughout their lifetime. This factorial arrangement allowed us to fully cross a source population (host co-occurrence) with a feeding regimen. Each cluster sampled contained from 4 to 17 eggs and corresponded to a maternal family in host plant treatments.

Like other species of Battus the larvae of B. polydamas remain gregarious from egg hatch up to the third instar, after which they feed solitarily (Pinto et al., 2009a). To mimic this behaviour larvae were reared in groups (about 2-9 larvae per Petri dish) until the beginning of the third instar (ca. 25 days) when all larvae were placed in separate plastic containers $(15 \times 15 \times 15 \mathrm{~cm})$. In the laboratory larvae were reared in growth chambers in order to keep the temperature $\left(14.8^{\circ} \mathrm{C}\right)$, humidity $(50 \%)$ and photoperiod (12 day light hours) relatively constant. Larvae were checked daily and fed with fresh leaves every other day until they pupated. Leaves used for feeding larvae were collected every other day from both sites to insure freshness. During every leaf collection, leaves that belonged to a particular Aristolochia species were combined to form a leaf batch independent of their origin. From these batches leaves were haphazardly sampled for feeding.

\section{Local larvae performance}

We recorded the performance and preference of the larvae of the two populations of $B$. polydamas. Performance was defined by how well individuals developed during the larval stages in terms of their development time, size and growth rate. Preference was defined in terms of the feeding choice of larvae offered both host species. Performance traits, such as development time, size and growth rate, and larval survival were quantified for individuals that were reared in the reciprocal transfer experiment. Preference (evaluated using a choice test with individuals of different families) was considered to be a reinforcing mechanism if coupled with performance.

Larval performance traits were recorded for individuals in all treatment combinations. We recorded survival and development time from egg to pupa. Relative growth rate (RGR) was calculated using the equation $\mathrm{RGR}=\left(\right.$ Mass at $\mathrm{t}_{2}-$ Mass at $\left.\mathrm{t}_{1}\right) /\left(\right.$ Mass at $\left.\mathrm{t}_{1}\right)$ $\left(t_{2}-t_{1}\right)$, where, Mass is caterpillar weight in $g$, $t_{1}$ was when the larvae were 10 days old (first instar) and $t_{2}$ when they were 45 days old (fifth instar). Finally, 50 days after the experiment began, size was estimated by measuring larval head width (pre-pupal stage).

We haphazardly chose 20 fifth-instar larvae, one per egg cluster, per treatment combination (host plant feeding regime $\times$ origin population) for the choice test. Larvae were starved for $10 \mathrm{~h}$ before the start of the experiment. Caterpillars were released singly at the base of a Y-tube olfactometer. Leaves of different host plants were placed at each end of the olfactometer's arms. Thus, at the Y-junction the caterpillar could choose between A. chilensis and A. bridgesii leaves. The behaviour of each insect was observed for up to ten minutes and choices were scored when the larvae took a path to one of the host plants.

\section{Host plant quality}

We conducted a no-choice test to assess whether host plants vary in quality for larvae from mixed and monospecific stands. For this we reared 40 larvae of $B$. polydamas (one per egg cluster, 20 per source population) on the host plants present at their original site until they reached the fifth instar $(\sim 45 \mathrm{~d})$ after which they were placed singly in a plastic container $\left(600 \mathrm{~cm}^{3}\right)$ and starved for $10 \mathrm{~h}$. The 20 larvae per source population were haphazardly divided in two and individuals from each half of the 10 containers were provided with fresh leaves daily from one of the Aristolochia species according to a factorial design $(10 \times$ source 
population $\times$ host plant). Both larvae and leaves were weighed just before the experiment began and then, $48 \mathrm{~h}$ later at the end of the trial. We quantified plant quality as the ratio between weight gain by larvae and leaf biomass consumed, which is an approximate measure of the contribution of plant tissue to larval growth (Rausher, 1981; Scriber \& Slansky, 1981).

\section{Data analysis}

To evaluate differences in host plant preference, we used a logit model with categorical predictors analyzed as a log-linear model (Agresti, 1996). The logit model had a binomial error and a loglink function using host choice (frequency of larvae choosing either host) as a dependent variable and host plant feeding regime and source population as main effects. Plant quality was evaluated in the same way but using a generalized linear model (GLM) with Gaussian error and an identity-link function. In this model the ratio between weight gain of each larva and the leaf biomass it consumed was used as the dependent variable and host plant feeding regime and source population the main effects. Models employed to evaluate differences in host plant preference and plant quality considered balanced designs and had sample sizes of 20 and 10 , respectively.

To quantify performance, we considered host plant species feeding regime, source population and families (random factor) nested within source population, as independent variables. Relative growth rate (RGR) and head size were also used as dependent variables but analyzed separately. In all three cases we used an analysis of variance for a nested design with random factors (nANOVA). Development time in days consisted of count data; therefore, significant treatment variation was assessed using a GLM with a Poisson error and a log-link function. In all models, we calculated interaction effects between host plant feeding regime and source population. In models where families were nested within localities that differ in host co-occurrence, significant differences indicate genetic differentiation in performance traits within populations. Although the experiment to evaluate differences in insect performance traits started with the same number of individuals (50), larval mortality during development and up to the time of measurement, resulted in sample sizes varying among traits. To avoid unbalanced designs, we removed all individuals that belonged to the same family from the analysis when one of the family members died before the measurement was taken. Therefore, the model for larval growth rate had a sample size of 32 and models used for head size and development time both had a sample size of 38 . Significant variation in the proportion of larvae that survived in each treatment was evaluated by fitting a GLM with a binomial error and a log-link function, and a sample size of 50 individuals. All analyses were done using the R statistical environment version 3.0.2 (R-Core team, 2013).

\section{RESULTS}

\section{Local larvae performance}

\section{Contribution of host plant preference}

The species of host plant fed to the larvae throughout their lifetime determined their preference $($ Estimate $=0.94$, $\mathrm{X}^{2}=11.70, \mathrm{P}$-value $\left.<0.001\right)$. Larvae chose the host plant on which they fed throughout their lifetime 2 to 4.3 times more often than the alternative plant. The population of origin (with differential host co-occurrence) did not influence larval choice $\left(\right.$ Estimate $=0.14, \mathrm{X}^{2}=0.22, \mathrm{P}$-value $>0.63$ ), nor was there a significant interaction between host plant feeding regime and source population (Estimate $=-0.25$, $\mathrm{X}^{2}=0.74$, P-value $>0.38$; Fig. 2).

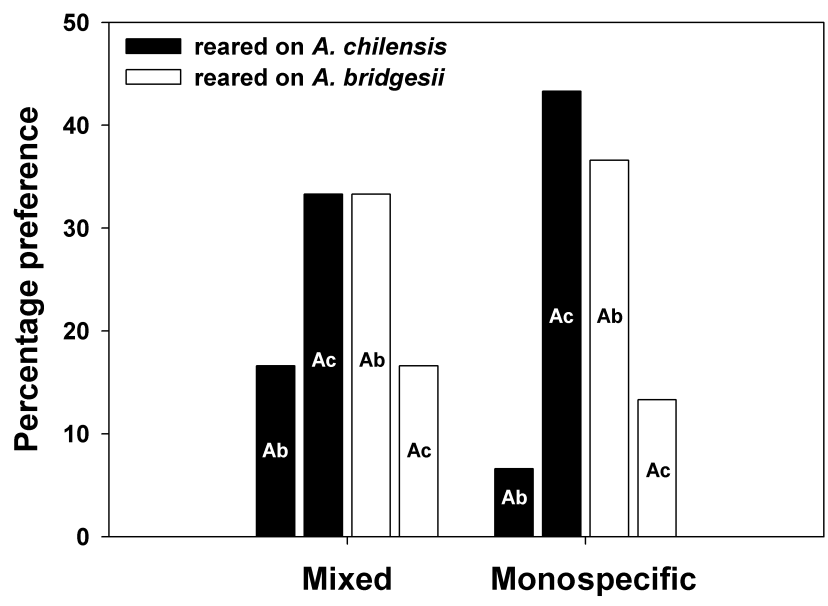

Fig. 2. Host plant preference of $B$. polydamas in relation to host co-occurrence and host plant feeding regime. The monospecific stand occurred at a locality with a large population of $A$. chilensis (Totoralillo), while the mixed stand occurred at a locality where both A. chilensis and A. bridgesii co-occur (Antakari). The percentage of the larvae from both types of stands that chose a host plant are shown in relation to host plant feeding experience. White bars are for larvae reared on $A$. bridgesii and black bars for larvae reared on $A$. chilensis. Letters within bars indicate the particular host chosen (Ab-A. bridgesii, Ac - A. chilensis). Data are for 15 individuals per treatment combination subject to a no choice test.

\section{Larval performance}

Larval growth rate did not depend on the source population $\left(\mathrm{F}_{1,132}\right.$-value $=0.15, \mathrm{P}$-value $\left.>0.70\right)$. Growth rate, however, varied depending on the host plant that larvae ate during their lifetime $\left(\mathrm{F}_{1,132}\right.$-value $=33.19$, P-value $<0.001$; Fig. 3a). On average, larvae that fed on $A$. bridgesii grew 1.4 times faster than larvae fed on $A$. chilensis. No evidence for a significant interaction between source population and host plant was found $\left(\mathrm{F}_{1,132}\right.$-value $=2.66, \mathrm{P}$-value $>0.10)$. There was, however, significant genetic variation in growth rate among families nested within source population $\left(\mathrm{F}_{83,132}\right.$-value $=2.61$, P-value $\left.<0.001\right)$.

Head size of larvae was on average 1.2 times greater when fed on $A$. bridgesii than on $A$. chilensis $\left(\mathrm{F}_{1,156}\right.$-value $=18.23$, P-value $<0.001$; Fig. $3 b)$. Size did not vary with source population $\left(\mathrm{F}_{1,156}\right.$-value $=0.64$, P-value $\left.>0.42\right)$; there was, however, a significant interaction between source population and host plant feeding regime $\left(\mathrm{F}_{1,156}{ }^{-}\right.$ value $=5.15, \mathrm{P}$-value $=0.025)$. Individuals from the monospecific stand (A. chilensis as the only host) that fed on $A$. bridgesii had the largest head size of all treatment combinations, whereas individuals from this same stand that fed on A. chilensis had the smallest. In addition, there was significant genetic variation in size among families nested within a source population $\left(\mathrm{F}_{23,156}\right.$-value $=2.24$, $\mathrm{P}$-value $=$ 0.002).

Larvae reached the pupal stage 1.2 times faster when they fed on $A$. bridgesii (Estimate $=-0.04, \mathrm{X}^{2}=7.71$, $\mathrm{P}$ value $=0.006$; Fig. $3 \mathrm{c}$ ). Source population alone did not determine development time (Estimate $=-0.01, \mathrm{X}^{2}=1.25$, $\mathrm{P}$-value $>0.26$ ). A significant interaction, however, between source population and feeding regime revealed that larvae from the monospecific stand feeding on $A$. chilensis took the longest time to reach the pupal stage, while indi- 

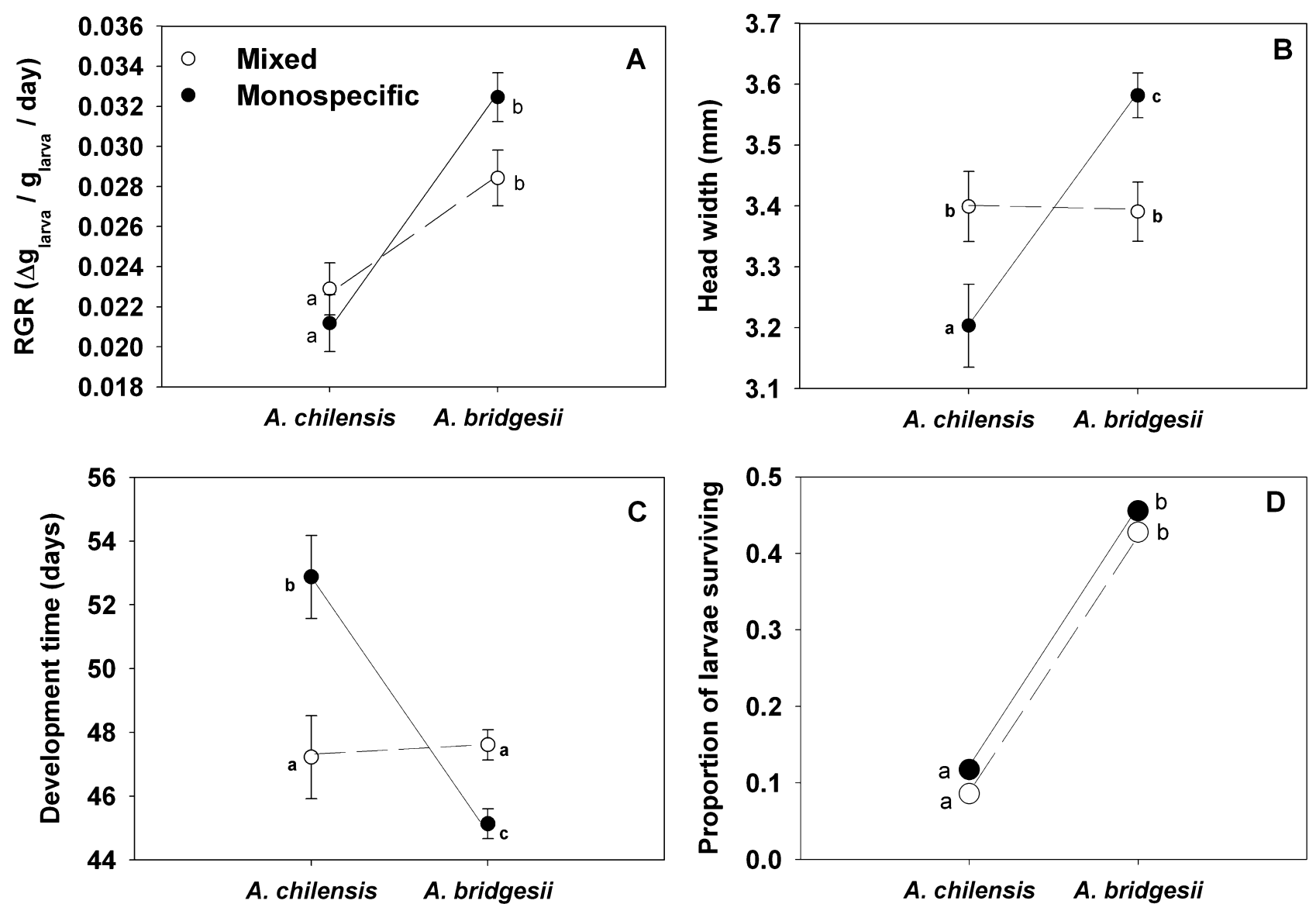

Fig. 3. Variation in performance traits and larval survival in relation to source populations that differ in host plant co-occurrence and host plant feeding regime. The monospecific stand occurred at a locality with a large population of $A$. chilensis (Totoralillo) and the mixed stand at a locality where both $A$. chilensis and $A$. bridgesii co-occur (Antakari). Larvae were reared on either $A$. bridgesii or $A$. chilensis throughout their larval development. A - relative growth rate (RGR); B - head size after 35 days used as a surrogate of larval size; $C$ - development time from egg to pupa; D - proportion of larvae that survived. Different letters indicate significant differences among treatment combinations (P-value $<0.05$, likelihood ratio tests). Error bars represent $1 \mathrm{SE}$ of the mean.

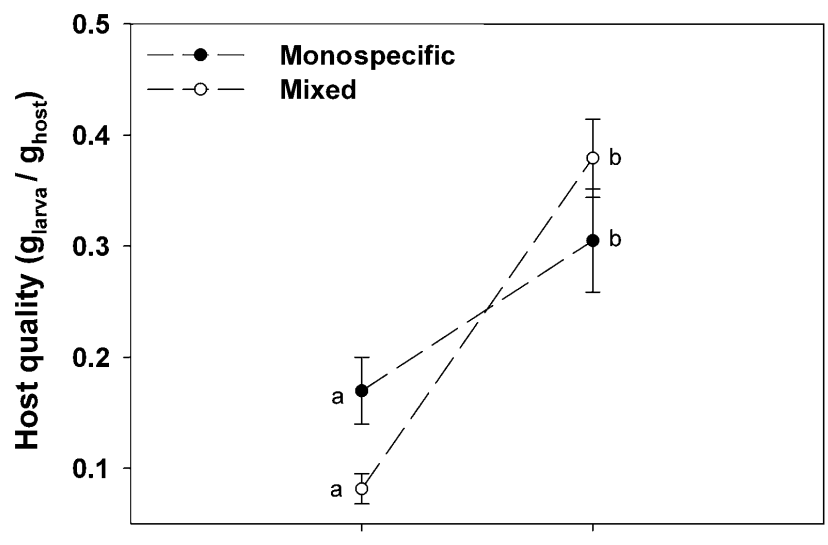

\section{A. chilensis A. bridgesii}

Fig. 4. Mean plant quality in the different host plant feeding regimes ( $A$. bridgesii and $A$. chilensis) for the larvae from localities that differed in host plant co-occurrence. The monospecific stand occurred at a locality with a large population of $A$. chilensis (Totoralillo) and the mixed stand at a locality where both $A$. chilensis and $A$. bridgesii co-occur (Antakari). Plant quality was assessed in terms of larval growth per unit of plant biomass ingested. Different letters indicate significant differences among treatment combinations $(P$-value $<0.05$, likelihood ratio tests). Error bars represent $1 \mathrm{SE}$ of the mean. viduals from this same stand that fed on $A$. bridgesii were the fastest in all treatment combinations (Estimate $=0.04$, $\mathrm{X}^{2}=9.79$, P-value $=0.002$ ).

Survival was on average 4.5 times higher when larvae fed on $A$. bridgesii compared to $A$. chilensis (Estimate $=$ $0.98, \mathrm{X}^{2}=101.4$, P-value $<0.001$; Fig. $3 d$ ). Survival, however, was independent of the source population (Estimate $=-0.11, \mathrm{X}^{2}=1.14, \mathrm{P}$-value $\left.>0.28\right)$ and there was no significant interaction between source population and host plant feeding regime (Estimate $=0.06, \mathrm{X}^{2}=0.29, \mathrm{P}$-value $>0.58)$.

\section{Host plant quality}

Larvae grew 3 times more when fed $A$. bridgesii compared to $A$. chilensis when they consumed the same amount of plant tissue $\left(\right.$ Estimate $=0.70, \mathrm{X}^{2}=8.04, \mathrm{P}$-value $=0.005$; Fig. 4). This pattern was independent of the source population $\left(\right.$ Estimate $=0.08, \mathrm{X}^{2}=0.11, \mathrm{P}$-value $>0.73$ ) and no significant interaction was evident with host plant feeding regime $\left(\right.$ Estimate $=0.24, \mathrm{X}^{2}=0.96, \mathrm{P}$-value $\left.>0.32\right)$.

\section{DISCUSSION}

Overall, our results show that host plants have a strong influence on important fitness components of $B$. poly- 
damas, such as its life history performance traits and larval survival. This is mainly due to differences in plant quality, which is associated with the variation in host plant (co-) occurrence between populations. Individuals from both populations developed best (i.e., shorter development time and greater larval size) and survived more when fed on $A$. bridgesii from mixed stands than on $A$. chilensis, which usually occurs in isolation. Overall, however, larval performance varied in an unexpected way because preference for and performance on the host plants have different roles as drivers of the recorded patterns in host utilization success and potential adaptive divergence between the two populations.

Optimal larvae performance would be facilitated if host preference was adaptive, that is, if individuals choose to feed on host plants that enhance their own long-term fitness (Scheirs et al., 2000). Results, however, indicate host plantinduced preference at the population scale. B. polydamas is a voracious herbivore whose late instar larvae find and recognize host plants using olfactory cues, the aristolochic acids present in Aristolochia (Pinto et al., 2009a). Larvae, however, are inclined to choose the Aristolochia species on which they fed during their development, regardless of its quality: relative preference was similar for both host plant treatments (ca. 75\%). Host preference appears to be dependent on previous feeding experience rather than a maternal imprint, even though the maternal provisioning documented for Battus species results in the transfer of aristolochic acids (AA) from adults to eggs (Urzúa et al., 1987; Fordyce et al., 2005).

Whether preference results in an adaptive or non-adaptive outcome will depend on the host on which the larvae developed and whether this host is associated with better performance and survival (Jaenike, 1978; Mayhew, 2001). For larvae exposed to a mixed host stand, host plant-induced preference can lessen performance by exposing individuals to stronger trade-offs in plant quality between plants given that individuals do not generally select the better quality host plant. These patterns, however, need to be viewed with caution because the preference trials were done under laboratory conditions and thus, not all aspects of preference and fitness were measured in these experiments (e.g., natural enemies). Thus, larval behaviour at the two localities might be adaptive in the broader context that induced these preferences.

Plant quality is a strong selective agent in determining the performance of herbivores (Awmack \& Leather, 2002). If differences in host quality are strong enough, they can drive variation in performance across herbivore populations (Laukkanen et al., 2012; Stotz et al., 2013). Specialist herbivores are often adapted to the chemical composition of their host plant (Fox \& Morrow, 1981; Kraft \& Denno, 1982; Bowers \& Puttick, 1988; Laukkanen et al., 2012), and can use putative defensive compounds as cues to locate their host or exploit those compounds for their own benefit (Bowers, 1983; Karban \& Agrawal, 2002) and $B$. polydamas is no exception. Unlike generalist herbivores, B. polydamas performs better on host plants with high lev- els of secondary compounds, as is common in other insect specialist (e.g., Bowers \& Puttick, 1988). Larvae of $B$. polydamas performed better on $A$. bridgesii although it contains almost twice as much AA as $A$. chilensis in terms of total yield and relative amount (Urzúa et al., 2009). Larvae tripled their weight gain per unit of plant biomass consumed when they fed on $A$. bridgesii compared to $A$. chilensis. Other studies have reported a similar pattern for B. polydamas: fewer larvae fed on leaves with low concentrations of AA survive and are smaller than those fed leaves with high levels of AA (e.g., Miller \& Feeny, 1989; Pinto et al., 2009a). Consequently, variation in life history performance between populations of $B$. polyadamas can be defined by the differences in host plant quality that result from variation in host plant co-occurrence in the two populations studied. Variability in host plant quality was greater in the mixed than in the monospecific stand.

Evidence for the above is the effect host-feeding regime has on life history traits. This effect is dependent on whether individuals of B. polydamas come from the mixed or the monospecific host stand. For instance, individuals from the mixed stand that were fed on A. chilensis were larger and developed faster than those from the monospecific stand fed on the same host. However, individuals from the mixed stand have a similar development time and are the same size when fed on $A$. bridgesii and $A$. chilensis, but their relative growth rate and survival were higher on $A$. bridgesii. Performance results indicate that the degree of local adaptation is relatively low and in particular, local maladaptation may even be occurring in the monospecific stand. On the one hand, host co-occurrence, may lessen performance at the mixed stand, possibly due to higher local variability there in host plant quality, differences in allelic expression and/or underlying trade-offs in performance on alternative host plants (Agrawal, 2000a, b; Kassen, 2002). On the other hand, if the only available host plant is of low quality, optimal performance on that plant may not be possible. This would occur if there is no genetic variation for either performance or preference within the population, diminishing a potential evolutionary response to the selective regime associated with the low quality host. Contrary to our predictions, the latter appears to be occurring in the monospecific host stand. Individuals from this stand performed better when they fed on a host that was not present in the stand where they occurred (i.e., A. bridgesii), suggesting that individuals from this population may be maladapted (sensu Crespi, 2000). Not only did larvae from the monospecific stand perform poorly in terms of all the life history traits recorded when they fed on their original host, $A$. chilensis, but survived better when they fed on $A$. bridgesii (a host not present where they were collected). Moreover, larvae from this population preferred the low-quality host in choice tests. Maladaptation is usually thought of as a result of lack of enough genetic variation for selection to act on, or, alternatively, due to weak selection (Crespi, 2000). In the monospecific population there was enough genetic variation in the performance traits (growth rate and larval size) for it to respond to selection. Thus, it is likely that 
selection imposed by the variation in the quality of a single host is insufficient to trigger a response in the population, unlike when more than one host is present.

We acknowledge, that our comparison is limited to two populations. Unfortunately, finding mixed stands with an adequate number of individuals of both insects and their host plants proved to be difficult. This difficulty raised the underlying conflict between a flawless experimental design and relevancy of the question addressed. Therefore, we explicitly delineate the scope of the results and the patterns recorded to the two populations studied and the information gained to a specific system. One should be cautious when extrapolating these results to a wider system of populations. Nevertheless, the variation recorded in this study is similar to that reported in previous findings. Studies that evaluate performance in plant-herbivore interactions have shown both that herbivores tend to be locally adapted to their host plants (e.g., Mopper et al., 1995; Van Zandt \& Mopper, 1998) or that host adaptation is absent (e.g., Strauss, 1997; Spitzer, 2006). The incidence and degree of performance on sympatric host plants are repeatedly found to vary among populations (e.g., Hanks \& Denno, 1994; Thompson, 2005; Ortegón-Campos et al., 2009). Here, we report evidence based on two populations that this phenomenon may be partly explained by differential cooccurrence of host plants that vary significantly in quality. The use of alternative host plants may result in divergent selection pressures across localities that, in the absence of other forces or constraints, could drive opposing adaptive processes. Moreover, host plant-induced preferences may impede adaptive host choices. Consideration of these phenomena may enhance our understanding of how performance evolves in specialized herbivorous insects.

ACKNOWLEDGEMENTS. We thank Y.P. Alcayaga, M.F. Cisternas and A.P. Loayza for their help in setting up experiments and fieldwork, as well as, the helpful encouragement provided by G.A. Rios and D.M. Rios. This work was supported by a postdoctoral grant from the Fondo Nacional de Desarrollo Científico y Tecnológico (FONDECYT-3120121) awarded to RSR.

\section{REFERENCES}

Agrawal A.A. 2000a: Specificity of induced resistance in wild radish: causes and consequences for two specialist and two generalist caterpillars. - Oikos 89: 493-500.

Agrawal A.A. 2000b: Host-range evolution: adaptation and trade-offs in fitness of mites on alternative hosts. - Ecology 81: 500-508.

Agresti A. 1996: An Introduction to Categorical Data Analysis. Wiley, New York, 400 pp.

Awmack C.S. \& Leather S.R. 2002: Host plant quality and fecundity in herbivorous insects. - Annu. Rev. Entomol. 47: $817-844$

Bolnick D.I., Yang L.H., Fordyce J.A., Davis J.M. \& SvanbäCK R. 2002: Measuring individual-level resource specialization. Ecology 83: 2936-2941.

BowERs M.D. 1983: The role of iridoid glycosides in host plant specificity of checkerspot butterflies. - J. Chem. Ecol. 9: 475-494.
Bowers M.D. \& Puttick G.M. 1988: Response of generalist and specialist insects to qualitative allelochemical variation. $-J$. Chem. Ecol. 14: 319-334.

CRESPI B.J. 2000: The evolution of maladaptation. - Heredity 84: 623-629.

Devictor V., Clavel J., Julliard R., Lavergne S., Mouillot D., Thuiller W., Venail P., Villéger S. \& Mouquet N. 2010: Defining and measuring ecological specialization. - J. Appl. Ecol. 47: 15-25.

EHRLICH P.R. \& RAVEN P.H. 1964: Butterflies and plants: a study in coevolution. - Evolution 18: 586-608.

EndLer J.A. 1977: Geographic Variation, Speciation and Clines. Princeton University Press, Princeton, NJ, 262 pp.

Fordyce J.A., Marion Z.H. \& Shapiro A.M. 2005: Phenological variation in chemical defense of the pipevine swallowtail. - $J$. Chem. Ecol. 31: 3835-2846.

Fox L.R. \& Morrow P.A. 1981: Specialization: Species property or local phenomenon. - Science 211: 887-893.

Futuyma D.J. \& Moreno G. 1988: The evolution of ecological specialization. - Annu. Rev. Ecol. Syst. 19: 207-233.

HANKs L.M. \& DenNo R.F. 1994: Local adaptation in the armored scale insect Pseudaulacaspis pentagona (Homoptera: Diaspididae). - Ecology 75: 2301-2310.

HEREFORD J. 2009: A quantitative survey of local adaptation and fitness trade-offs. - Am. Nat. 173: 579-588.

HougEn-EItzman D. \& RAUSHER M.D. 1994: Interactions between herbivorous insects and plant-insect coevolution. - Am. Nat. 143: 677-697.

How S.T., Abrahamson W.G. \& Craig T.P. 1993: Role of host plant phenology in host use by Eurosta solidaginis (Diptera: Tephritidae) on Solidago (Compositae). - Environ. Entomol. 22: 388-396.

JAENIKE J. 1978: On optimal oviposition behaviour in phytophagous insects. - Theor. Popul. Biol. 14: 350-356.

JAENIKE J. 1990: Host specialization in phytophagous insects. Annu. Rev. Ecol. Syst. 21: 243-273.

JAENIKE J. \& PAPAJ D.R. 1992: Learning and patterns of host use by insects. In Isman M.B. \& Roitberg B.D. (eds): Chemical Ecology: An Evolutionary Perspective. Chapman and Hall, New York, pp. 245-264.

Karban R. \& Agrawal A.A. 2002: Herbivore offense. - Annu. Rev. Ecol. Syst. 33: 641-664.

KASSEN R. 2002: The experimental evolution of specialists, generalists, and the maintenance of diversity. - J. Evol. Biol. 15: 173-190.

KAWECKI T.J. 1994: Accumulation of deleterious mutations and the evolutionary cost of being a generalist. - Am. Nat. 144: 833-838.

KAWECKI T.J. \& EBERT D. 2004: Conceptual issues in local adaptation. - Ecol. Lett. 7: 1225-1241.

Kraft S.A. \& Denno R.F. 1982: Feeding responses of adapted and non-adapted insects of the defensive properties of Baccharis halimifolia L. (Compositae). - Oecologia 52: 156-163.

Laukkanen L., Leimu R., Muola A., Lilley M., Salminen J.-P. \& MUtikAINEN P. 2012: Plant chemistry and local adaptation of a specialized folivore. - PLOS ONE 7: e38225, 8 pp.

MAYHEW P.J. 2001: Herbivore host choice and optimal bad motherhood. - Trends Ecol. Evol. 16: 165-167.

MilLER J.J. \& FeENy P.P. 1989: Interspecific differences among swallowtail larvae (Lepidoptera: Papilionidae) in susceptibility to aristolochic acids and berberine. - Ecol. Entomol. 14: 287-296.

Mopper S., Beck M., Simberloff D. \& Stiling P. 1995: Local adaptation and agents of selection in a mobile insect. - Evolution 49: 810-815. 
Ortegón-Campos I., Parra-Tabla V., Abdala-Roberts L. \& HerRERA C.M. 2009: Local adaptation of Ruellia nudiflora (Acanthaceae) to counterparts: complex scenarios revealed when two herbivore guilds are considered. - J. Evol. Biol. 22: 22882297.

Peña L.E. \& Ugarte A.J. 1996: Mariposas de Chile. Editorial Universitaria, Santiago, Chile, 359 pp.

Pinto C.F., Troncoso A.J., Urzúa A. \& Niemeyer H.M. 2009a: Use of volatiles of Aristolochia chilensis (Aristolochiaceae) in host searching by fourth-instar larvae and adults of Battus polydamas archidamas (Lepidoptera: Papilionidae: Troidini). - Eur. J. Entomol. 106: 63-68.

Pinto C.F., Troncoso A.J., Urzúa A. \& Niemeyer H.M. 2009b: Aristolochic acids affect the feeding behaviour and development of Battus polydamas archidamas larvae (Lepidoptera: Papilionidae: Troidini). — Eur. J. Entomol. 106: 357-361.

Pinto C.F., Urzúa A. \& Niemeyer H.M. 2011: Sequestration of aristolochic acids from meridic diets by larvae of Battus polydamas archidamas (Papilionidae: Troidini). — Eur. J. Entomol. 108: 41-45.

Poisot T., Bever J.D., Nemri A., Thrall P.H. \& Hochberg M.E. 2011: A conceptual framework for the evolution of ecological specialisation. - Ecol. Lett. 14: 841-851.

Poonam V.K., Prasad A.K. \& Parmar V.S. 2003: Naturally occurring aristolactams, aristolochic acids and dioxoaporphines and their biological activities. - Prod. Rep. 20: 565-583.

R Core Team 2013: $R$ : A Language and Environment for Statistical Computing. R Foundation for Statistical Computing, Vienna, Austria, URL: http://www.Rproject.org/.

RAUSHER M.D. 1981: Host plant selection by Battus philenor butterflies: the roles of predation, nutrition, and plant chemistry. - Ecol. Monogr. 51: 1-20.

Reznick D.N. \& Ghalambor C.K. 2001: The population ecology of contemporary adaptations: what empirical studies reveal about the conditions that promote adaptive evolution. - Genetica 112-113: 183-198.

Riedemann P., Aldunate G. \& Teillier S. 2006: Flora Nativa de Valor Ornamental: Identificación y Propagación Chile Zona Norte. Productora Gráfica Andros, Chile, 404 pp.

SAChDEV-GuPtA K., FeENy P.P. \& CARTer M. 1993: Oviposition stimulants for the pipevine swallowtail butterfly, Battus philenor (Papilionidae), from an Aristolochia host plant: synergism between inositols, aristolochic acids and monogalactosyl diglyceride. - Chemoecology 4: 19-28.

Scheirs J., De Bruyn L. \& Verhagen R. 2000: Optimization of adult performance determines host choice in a grass miner. Proc. R. Soc. Lond. (B) 267: 2065-2069.
SCRIBER J.M. \& SLANSKy F. 1981: The nutritional ecology of immature insects. - Annu. Rev. Entomol. 26: 183-211.

SpITZER B. 2006: Local maladaptation in the soft scale insect Saissetia coffeae (Hemiptera: Coccidae). — Evolution 60: 18591867.

Stotz G.C. \& Gianoli E. 2013: Pollination biology and floral longevity of Aristolochia chilensis in an arid ecosystem. - Plant Ecol. Divers. 6: 181-186.

Stotz G.C., Suárez L.H., GonzÁles W.L. \& Gianoli E. 2013: Local host adaptation and use of a novel host in the seed beetle Megacerus eulophus. - PLoS ONE 8: e53892, 5 pp.

StRAUSS S.Y. 1997: Lack of evidence for local adaptation to individual plant clones or site by a mobile specialist herbivore. -Oecologia 110: 77-85.

THompson J.N. 1999: Specific hypotheses on the geographic mosaic of coevolution. - Am. Nat. 153: 1-4.

Thompson J.N. 2005: The Geographic Mosaic of Coevolution. University Chicago Press, Chicago, 400 pp.

Thompson J.N. \& Cunningham B.M. 2002: Geographic structure and dynamics of coevolutionary selection. - Nature 417: 735-738.

Tолч H. \& Sота T. 2006: Imbalance of predator and prey armament: geographic clines in phenotypic interface and natural selection. - Am. Nat. 167: 105-117.

Urzúa A., Rodríguez R. \& Cassels B.K. 1987: Fate of ingested aristolochic acids in Battus polydamas archidamas. - Biochem. Syst. Ecol. 15: 687-689.

Urzúa A., Santander R. \& Sotes G. 2009: Aristoloic acids from Aristolochia bridgesii, a host-plant of Battus polydamas archidamas. - J. Chil. Chem. Soc. 54: 437-438.

VAN ZANDT P.A. \& Mopper S. 1998: A meta-analysis of adaptive deme formation in phytophagous insect populations. - Am. Nat. 152: 595-604.

VIA S. 1990: Ecological genetics and host adaptation in herbivorous insects: the experimental study of evolution in natural and agricultural systems. - Annu. Rev. Entomol. 35: 421-446.

VIA S. \& LANDE R. 1985: Genotype-environment interaction and the evolution of phenotypic plasticity. - Evolution 39: 505522.

WhiтLоск M.C. 1996: The red queen beats the jack-of-all-trades: the limitations on the evolution of phenotypic plasticity and niche breadth. - Am. Nat. 148: S65-S77.

Zangerl A.R. \& Berenbaum M.R. 2003: Phenotype matching in wild parsnips and parsnip webworms: causes and consequences. - Evolution 57: 806-815.

Received March 2, 2015; revised and accepted December 8, 2015 Published online February 5, 2016 